12,13

\title{
Модифицирование структуры многостенных углеродных нанотрубок с использованием непрерывного и импульсного ионных пучков
}

\author{
(C) П.М. Корусенко ${ }^{1,4}$, С.Н. Несов ${ }^{1}$, С.Н. Поворознюк ${ }^{1,2,}$, В.В. Болотов ${ }^{1}$ \\ Е.В. Князев ${ }^{1}$, А.И. Пушкарев ${ }^{3}$, Д.А. Смирнов ${ }^{4,5}$ \\ ${ }^{1}$ Омский научный центр СО РАН, \\ Омск, Россия \\ ${ }^{2}$ Омский государственный технический университет, \\ Омск, Россия \\ ${ }^{3}$ Национальный исследовательский Томский политехнический университет, \\ Томск, Россия \\ ${ }^{4}$ Санкт-Петербургский государственный университет, \\ Санкт-Петербург, Россия \\ ${ }^{5}$ Institute of Solid State Physics, Dresden University of Technology, \\ Dresden, Germany \\ E-mail: korusenko@obisp.oscsbras.ru
}

(Поступила в Редакцию 10 мая 2018 г.)

Методами просвечивающей электронной микроскопии, ренгенофотоэлектронной (XPS) и рентгеновской спектроскопии поглощения (XANES) исследовано изменение локальной атомной и электронной структуры, а также химического состояния поверхности многостенных углеродных нанотрубок (МУНТ) вследствие воздействия непрерывного и импульсного ионных пучков. Показано, что при облучении непрерывным пучком ионов аргона изменение структуры и химического состояния МУНТ обусловлены радиационноиндуцированным формированием дефектов. При использовании углерод-протонного импульсного пучка существенное влияние на изменение структуры углеродных нанотрубок оказывает термическое воздействие. Результаты работы показывают, что применение непрерывных и импульсных ионных пучков может быть использовано для направленной функционализации физико-химических свойств МУНТ.

Исследование выполнено по государственному заданию ОНЦ СО РАН в соответствии с Программой фундаментальных научных исследований государственных академий наук на 2013-2020 годы по направлению II.9, проект № II.9.2.1 (номер госрегистрации в системе ЕГИСУ НИОКТР AАAА-A17-117041210227-8) и при частичной финансовой поддержке РФФИ в рамках научных проектов № 18-32-00233 мол_а (в части исследования структуры МУНТ, облученных пучком ионов аргона), № 16-08-00763 а (в части исследования методом ПЭМ).

DOI: $10.21883 /$ FTT.2018.12.46773.126

\section{1. Введение}

В настоящее время высокий интерес в области материаловедения вызывает разработка новых материалов на основе многостенных углеродных нанотрубок (МУНТ), которые обладают высокими механическими характеристиками, электрическими и теплопроводящими свойствами $[1,2]$. Однако, структура и химическое состояние поверхности получаемых МУНТ зачастую не обеспечивает требуемых физико-химических свойств. Для применения МУНТ в качестве чувствительных элементов газовых сенсоров и эмиттеров необходимо в первую очередь контролировать электронные свойства поверхности углеродных нанотрубок: тип проводимости, концентрацию свободных носителей заряда, работу выхода электрона и др. [3,4]. При создании новых композитных материалов на основе МУНТ и металлов или их оксидов, а также полимеров, определяющую роль играет взаимодействие компонентов композитов на межфазных границах [5]. Как правило, МУНТ, слабо взаимодействуют с металлами, оксидами металлов и полимерами, что может приводить к ухудшению эксплуатационных характеристик получаемых композитов: межфазной адгезии, механической прочности, электрической проводимости идр. Для модифицирования поверхности МУНТ применяются различные методы функционализации, позволяющие влиять на структуру, химическое состояние и электронные характеристики. Одним из способов повышения химической активности поверхности МУНТ является функционализация углеродных нанотрубок с применением ионно-плазменных методов обработки [6]. При воздействии непрерывных пучков ионов со средней энергией в диапазоне $0.05-100$ кэВ одним из основных механизмов поглощения их энергии в материалах является упругое рассеяние на атомах мишени с образованием первичных радиационных дефектов (пар Френкеля) [7,8]. Формирование структурных дефектов (оборванные связи, вакансии и их комплексы, адатомы и др.) в стенках МУНТ приводит к присоединению различных функциональных групп и изменению 
физико-химических свойств поверхности углеродных нанотрубок [9]. В частности, наличие кислородсодержащих групп на поверхности МУНТ влияет на концентрацию носителей заряда, тип проводимости, работу выхода электрона, а также способно повысить адгезию металлов, их оксидов и полимеров к стенкам углеродных нанотрубок [4,5]. Новое направление для функционализации поверхности МУНТ основано на применении импульсного ионного пучка высокой удельной мощности $\left(10^{5}-10^{10} \mathrm{~W} / \mathrm{cm}^{2}\right)[10]$. Импульсно-пучковое воздействие сопровождается сверхбыстрым нагревом и остыванием (до $10^{11} \mathrm{~K} / \mathrm{s}$ ), высокими градиентами температуры и давления, что приводит к изменению морфологии, электронной структуры, а также к возможному формированию новых фазовых состояний в материале [11]. Средняя энергия ионов при импульсно-пучковом облучении обычно составляет более 100 кэВ. При этом поглощения энергии налетающих ионов в материалах осуществляется преимущественно за счет неупругого рассеяния. Поскольку импульсный ионный пучок обладает низким флюенсом за импульс облучения $\left(<10^{15} \mathrm{ion} / \mathrm{cm}^{2}\right)$, основной причиной изменения структуры материалов является термическое воздействие высокоэнергетических ионов [11]. При этом влияние такого вида энергетического воздействия на наноструктурированные углеродные материалы, в частности МУНТ, практически не изучено.

В настоящей работе проведено исследование структуры и химического состояния МУНТ, модифицированных пучками ионов различной интенсивности. Проведен анализ изменения локальной атомной и электронной структуры МУНТ, а также количества и типов функциональных групп, формируемых на поверхности углеродных нанотрубок, вследствие ионно-пучкового воздействия. Для характеризации МУНТ были использованы метод электронной микроскопии и методы рентгенофотоэлектронной (XPS - X-ray Photoelectron Spectroscopy), рентгеновской спектроскопии поглощения (XANES - X-ray Absorption Near Edge Spectroscopy), реализованные с использованием синхротронного излучения.

\section{2. Эксперимент}

Массивы МУНТ были синтезированы с использованием химического газофазного осаждения на подложках $\mathrm{Si} / \mathrm{SiO}_{2}$ при пиролизе смеси ацетонитрила с ферроценом $(100: 1)$ при температуре $800^{\circ} \mathrm{C}$. Синтез продолжался в течение $15 \mathrm{~min}$. Средняя толщина выращенных массивов МУНТ составляла $\sim 11 \mu \mathrm{m}$. Синтезированные МУНТ содержали примесь азота $(\sim 2$ at.\%) в виде пиридиновых, пиррольных и графитовых дефектов, а также азота в молекулярном состоянии $\left(\mathrm{N}_{2}\right)$ в межстеночном пространстве МУНТ и в их полостях [10].

Модифицирование МУНТ проводилось ионными пучками различной интенсивности: непрерывным пучком ионов аргона с использованием установки для ионной имплантации и импульсным углерод-протонным пуч- ком на ускорителе ТЕМП-4М [12]. Средняя энергия ионов аргона при облучении непрерывным пучком составляла $\sim 5 \mathrm{keV}$, а флюенс ионов составлял $1 \cdot 10^{16}$ и $5 \cdot 10^{16} \mathrm{ion} / \mathrm{cm}^{2}$. При облучении импульсным ионным пучком средняя энергия ионов составляла $250 \mathrm{keV}$, длительность импульса $-120 \mathrm{~ns}$, плотность энергии - 0.5 и $1.5 \mathrm{~J} / \mathrm{cm}^{2}$. Флюенс ионов углерод-протонного пучка составлял $\sim 10^{14} \mathrm{ion} / \mathrm{cm}^{2}$ за импульс. Давление остаточных газов при облучении непрерывным и импульсным ионными пучками составляло $10^{-4}$ Torr. Проективный пробег ионов аргона, протонов и ионов углерода в слое МУНТ оценен с использованием программного пакета SRIM [13] и составлял $\sim 0.1 \mu \mathrm{m}, 11.4 \mu \mathrm{m}$ и $4.7 \mu \mathrm{m}$ соответственно. При расчетах использовалась экспериментально вычисленная плотность массива МУНТ, которая составляла $0.2 \mathrm{~g} / \mathrm{cm}^{3}$.

Исследование структуры МУНТ методом просвечивающей электронной микроскопии (ПЭМ) проводилось на электронном микроскопе JEOL JEM 2100 и JEOL JEM $2200 \mathrm{FS}$.

Анализ локальной атомной структуры и химического состояния МУНТ был осуществлен с использованием методов XPS и XANES на оборудовании станции RGL синхротронного накопителя BESSY II (Берлин, Германия). Обзорные XPS спектры регистрировались при энергии фотонов $850 \mathrm{eV}$. При измерении спектров валентной зоны использовались фотоны с энергией $125 \mathrm{eV}$. Согласно расчетам Тanuma и др. [14], глубина выхода фотоэлектронов валентной зоны при возбуждении с указанными энергиями, составляет не более $1 \mathrm{~nm}$. XANESспектры C $K$-края поглощения углерода регистрировались в режиме измерения тока утечки при энергетическом разрешении монохроматора не хуже $\sim 0.1 \mathrm{eV}$. Для нормировки XANES-спектров применялась процедура деления регистрируемого сигнала на ток, измеренный с пластинки чистого золота. Глубина анализа данным методом составляла $\sim 15 \mathrm{~nm}$ [15]. Измерения XPS- и XANES-спектров проводились в сверхвысоком вакууме при давлении остаточных газов в измерительной камеpe $\sim 10^{10}$ Torr.

\section{3. Результаты и их обсуждение}

\section{1. Исследование структуры МУНТ}

На рис. 1 приведены ПЭМ-изображения МУНТ до и после облучения непрерывным и импульсным ионными пучками. Из рис. 1, $a$ видно, что исходные МУНТ обладают бамбукообразной структурой, характерной для углеродных нанотрубок синтезированных с использованием ацетонитрила [16]. На вставке рис. 1, $a$ видно, что МУНТ имеет достаточно высокую степень упорядоченности кристаллической структуры, однако внешние слои МУНТ содержат определенные дефекты структуры: наблюдаются заметные изгибы отдельных слоев, обрывы и слияние отдельных графеновых плоскостей. Как видно 

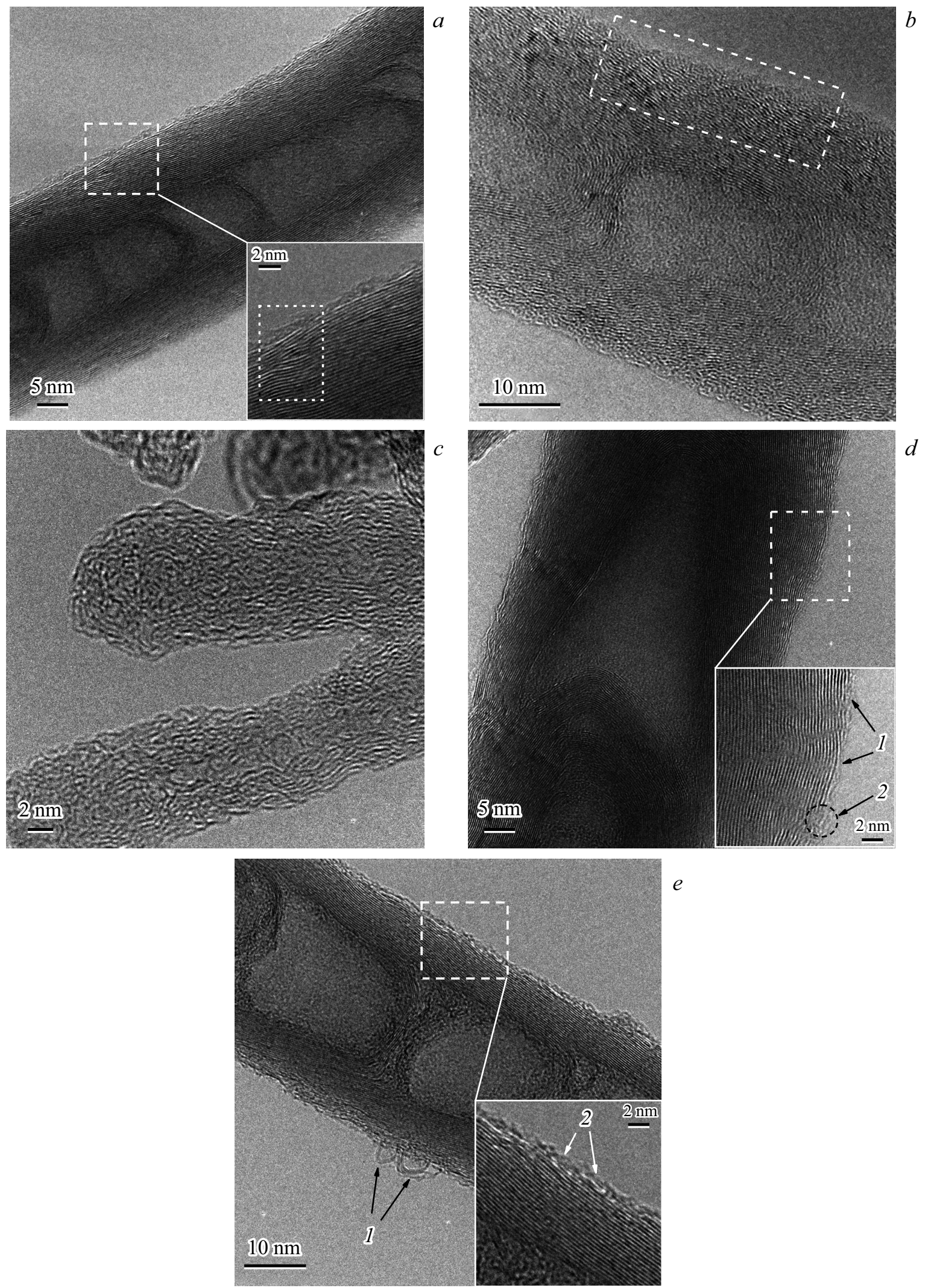

Рис. 1. ПЭМ-изображение: $a$ - исходных МУНТ; МУНТ, облученных ионами аргона с различным флюенсом: $b-1 \cdot 10^{16}$ ion $/ \mathrm{cm}^{2}$, $c-5 \cdot 10^{16} \mathrm{ion} / \mathrm{cm}^{2}$; МУНТ, облученных импульсным ионным пучком с плотностью энергии $d-0.5 \mathrm{~J} / \mathrm{cm}^{2}, e-1.5 \mathrm{~J} / \mathrm{cm}^{2}$. Цифрами на рисунке обозначены: 1 - фрагменты графеновых слоев, 2 - слабоструктурированные углеродные образования. 
(рис. $1, b, c)$, облучение непрерывным пучком ионов аргона приводит к значительному повышению дефектности стенок МУНТ по всей ее толщине: наблюдаются множественные разрывы графеновых слоев с формированием отдельных фрагментов, различно ориентированных относительно продольной оси МУНТ [17]. При этом увеличение флюенса ионов приводит к повышению степени разупорядоченности кристаллической структуры МУНТ (рис. 1,c).

На ПЭМ-изображении МУНТ, облученных импульсным ионным пучком (рис. $1, d$ ) не наблюдается значительных изменений структуры по сравнению с исходными углеродными нанотрубками, что, по-видимому, обусловлено низким флюенсом за импульс $\left(\sim 10^{14}\right.$ ion $\left./ \mathrm{cm}^{2}\right)$. Заметные нарушения кристаллической структуры МУНТ присутствуют только на отдельных участках поверхностных слоев: наблюдаются разрывы графеновых слоев, наличие слабоструктурированных углеродных образований на поверхности МУНТ. Как видно (рис. $1, e)$ при более высокой плотности энергии облучения наблюдается повышение степени упорядоченности кристаллической структуры стенок углеродных нанотрубок. Мы предполагаем, что снижение дефектности структуры МУНТ происходит за счет кристаллизации, протекающей вследствие нагрева (до $\sim 1800^{\circ} \mathrm{C}[10]$ ) под воздействием импульсного ионного пучка. Однако на поверхности МУНТ наблюдается наличие структурных дефектов вакансионного типа и фрагментов графеновых плоскостей, которые предположительно могут возникать вследствие радиационного воздействия и возникновения термических напряжений под влиянием импульсного ионного пучка.

\section{2. Анализ локальной атомной структуры и химического состояния МУНТ}

На рис. 2 приведены обзорные XPS-спектры МУНТ до и после облучения непрерывным и импульсным ионными пучками. Как видно, во всех спектрах наблюдаются линии углерода $\mathrm{C} 1 s(\sim 285 \mathrm{eV})$, линии оже-переходов O KLL $(\sim 343 \mathrm{eV})$, азота $\mathrm{N} 1 s(\sim 401 \mathrm{eV})$, кислорода $\mathrm{O} 1 s \quad(\sim 533 \mathrm{eV})$, и линии оже-переходов С $K L L$ $(\sim 590 \mathrm{eV})$. Анализ обзорных XPS-спектров облученных MУНТ (рис. 2, кривые 2, 4,5) показал существенное увеличение интенсивности кислородных линий О $1 s$ в сравнении с исходными углеродными нанотрубками (рис. 2, вставка). Однако в спектре МУНТ, облученных импульсным ионным пучком с плотностью энергии $1.5 \mathrm{~J} / \mathrm{cm}^{2}$ интенсивность линии кислорода снижается практически до уровня фона (рис. 2, кривая 3). Данные количественного расчета, полученные по результатам анализа обзорных XPS-спектров, показывают, что после облучения ионами аргона с различным флюенсом и импульсным ионным пучком с плотностью энергии $0.5 \mathrm{~J} / \mathrm{cm}^{2}$ содержание кислорода на поверхности МУНТ увеличивается (таблица). Высокое содержание кислорода связано с формированием точечных и объемных структурных дефектов,

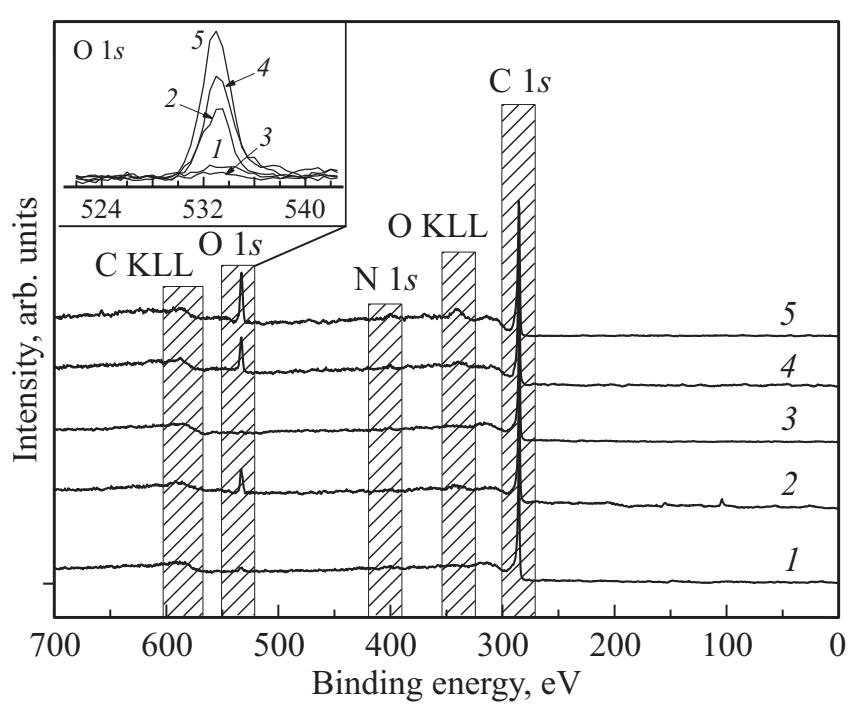

Рис. 2. Обзорные XPS-спектры МУНТ: 1 - исходных; облученных импульсным ионным пучком с плотностью энергии $2-0.5 \mathrm{~J} / \mathrm{cm}^{2}, 3-1.5 \mathrm{~J} / \mathrm{cm}^{2}$; облученных ионами аргона с различным флюенсом $4-1 \cdot 10^{16} \mathrm{ion} / \mathrm{cm}^{2}, 5-5 \cdot 10^{16} \mathrm{ion} / \mathrm{cm}^{2}$.

оборванных химических связей и адатомов на внешних стенках МУНТ в результате облучения и закреплением на них функциональных кислородсодержащих групп различного состава $[18,19]$. Снижение концентрации кислорода в МУНТ, облученных импульсным ионным пучком с плотностью энергии $1.5 \mathrm{~J} / \mathrm{cm}^{2}$ вероятно обусловлено термически инициированным разрушением кислородсодержащих групп на поверхности МУНТ вследствие воздействия пучка.

Анализ состава функциональных групп, формирующихся в результате облучения, проводился с использованием XANES-спектров C $K$-края поглощения углерода. В спектре поглощения углерода исходных МУНТ (рис. 3, кривая 1) наблюдается интенсивный и узкий $\pi^{*}(\mathrm{C}=\mathrm{C})$-резонанс на энергии фотонов $\sim 285 \mathrm{eV}$, $\sigma^{*}(\mathrm{C}=\mathrm{C})$-резонанс, обладающий двумя локальными максимумами на энергии фотонов $\sim 291.7$ и $\sim 292.8 \mathrm{eV}$,

Значение концентрации элементов для МУНТ до и после облучения по данным XPS

\begin{tabular}{l|c|c|c}
\hline \multirow{2}{*}{ Параметры облучения } & \multicolumn{3}{|c}{ Концентрация, at. } \\
\cline { 2 - 4 } & $\mathrm{C}$ & $\mathrm{N}$ & $\mathrm{O}$ \\
\hline Исходные МУНТ & 96.5 & 2.2 & 1.3 \\
\hline \multicolumn{4}{c}{ Непрерывный пучок ионов аргона } \\
\hline $1 \cdot 10^{16} \mathrm{ion} / \mathrm{cm}^{2}$ & 90.2 & 1.6 & 8.2 \\
$5 \cdot 10^{16} \mathrm{ion} / \mathrm{cm}^{2}$ & 87.5 & 1.4 & 11.1 \\
\hline \multicolumn{4}{c}{ Импульсный ионный пучок } \\
\hline $0.5 \mathrm{~J} / \mathrm{cm}^{2}$ & 92.7 & 1.3 & 6.0 \\
$1.5 \mathrm{~J} / \mathrm{cm}^{2}$ & 99.3 & 0 & 0.7
\end{tabular}




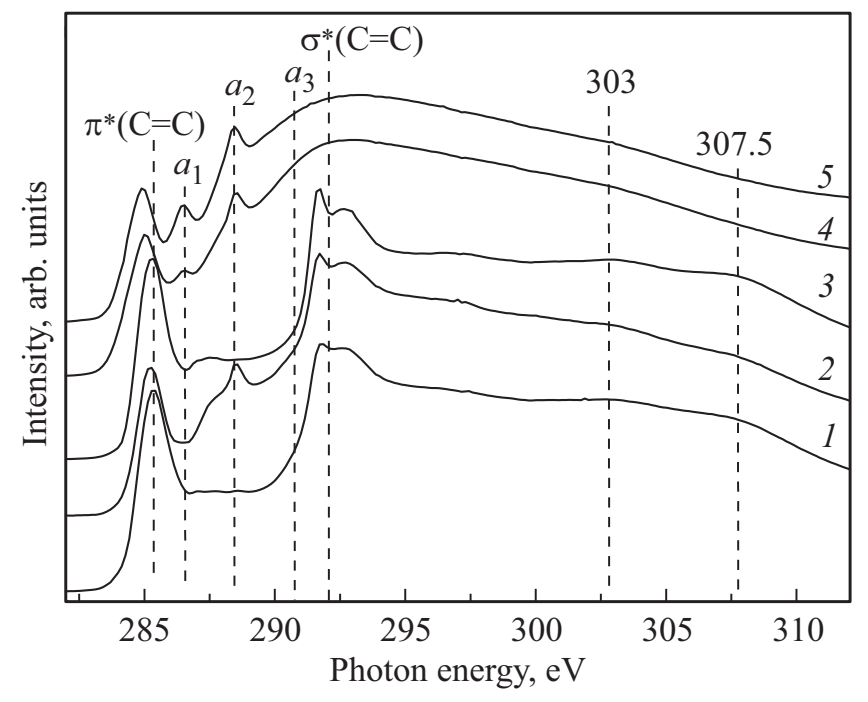

Рис. 3. XANES-C $K$ спектры MУНT: 1 - исходных; облученных импульсным ионным пучком с плотностью энергии $2-0.5 \mathrm{~J} / \mathrm{cm}^{2}, 3-1.5 \mathrm{~J} / \mathrm{cm}^{2}$; облученных ионами аргона с различным флюенсом $4-1 \cdot 10^{16}$ ion $/ \mathrm{cm}^{2}, 5-5 \cdot 10^{16}$ ion $/ \mathrm{cm}^{2}$.

что свидетельствует о достаточно высокой степени кристаллического порядка стенок МУНТ [20]. Наличие разрешенных локальных максимумов на энергии фотонов $\sim 303$ и $\sim 307 \mathrm{eV}$ также указывает на низкую степень дефектности МУНТ [20]. В XANES-спектре углерода МУНТ, облученных импульсным ионным пучком с плотностью энергии $0.5 \mathrm{~J} / \mathrm{cm}^{2}$ (рис. 3, кривая 2), наблюдается существенное снижение интенсивности $\pi^{*}(\mathrm{C}=\mathrm{C})$-резонанса и наличие дополнительных особенностей $\left(a_{2}\right),\left(a_{3}\right)$ на энергиях фотонов $\sim 288.5$ и $\sim 290.7 \mathrm{eV}$ соответственно. Максимум $\left(a_{2}\right)$ отвечает $\pi^{*}(\mathrm{C}=\mathrm{O})$-состояниям в составе карбоксильных $(\mathrm{COOH})$ или карбонильных $(\mathrm{C}=\mathrm{O})$ групп, а максимум $\left(a_{3}\right)-$ $\sigma^{*}(\mathrm{C}-\mathrm{O})$ состояниям в составе эфирных $(\mathrm{C}-\mathrm{O})$, эпоксидных (C-O-C) и карбонатных групп $\left(\mathrm{CO}_{3}\right)[19,21]$. Кроме этого, в высокоэнергетической области спектра поглощения углерода наблюдается размытие дальнего края поглощения на энергиях 297-312 eV. Bсе это указывает на искажения графитовой структуры стенок МУНТ вследствие формирования в них структурных дефектов, в том числе, атомов углерода в $s p^{3}$-гибридизации, а также функциональных кислородсодержащих групп. Однако, в данном спектре поглощения также наблюдается увеличение интенсивности максимума на энергии фотонов $291.7 \mathrm{eV}$ в структуре $\sigma^{*}(\mathrm{C}=\mathrm{C})$-резонанса. Наличие высокоинтенсивного максимума на энергии фотонов $291.7 \mathrm{eV}$ характерно для спектров высокоупорядоченных графитовых структур (пиролитический графит и др.) [22]. Таким образом, полученные результаты свидетельствуют о неоднородности структуры и состава стенок углеродных нанотрубок после облучения. Мы предполагаем, что при облучении импульсным ионным пучком с плотностью энер- гии $0.5 \mathrm{~J} / \mathrm{cm}^{2}$ формирование структурных дефектов происходит преимущественно на внешних стенках МУНТ. При этом во внутренних стенах МУНТ происходит отжиг дефектов кристаллической структуры вследствие термического нагрева под влиянием импульсного ионного пучка. Облучение при указанной плотности энергии способно приводить к нагреву приповерхностной области слоя МУНТ до $\sim 800^{\circ} \mathrm{C}[10]$. В пользу предположения о термическом отжиге дефектов при импульсном ионном облучение свидетельствуют форма XANES спектра МУНТ, облученного импульсным ионным пучком с плотностью энергии $1.5 \mathrm{~J} / \mathrm{cm}^{2}$ (рис. 3, кривая 3), в котором отсутствуют состояния, отвечающие углеродкислородным химическим связям, наблюдается увеличение интенсивности $\pi^{*}(\mathrm{C}=\mathrm{C})$-резонанса и максимума на $\sim 291 \mathrm{eV}$ в структуре $\sigma^{*}(\mathrm{C}=\mathrm{C})$-резонанса. Кроме этого, тонкая структура XANES-спектров в высокоэнергетической области (294-312 eV) идентична структуре спектра исходных МУНТ. Это свидетельствует о повышении степени кристалличности структуры стенок МУНТ, что согласуется с данными ПЭМ (рис. $1, e$ ).

B XANES спектрах углерода облученных ионами аргона МУНТ наблюдаются значительные изменения (рис. 3, кривые 4 и 5) относительно спектра исходных МУНТ, а именно: существенное падение $\pi^{*}(\mathrm{C}=\mathrm{C})$-резонанса и сдвиг максимума резонанса в низкие энергии фотонов, потеря тонкой структуры $\sigma^{*}(\mathrm{C}=\mathrm{C})$-резонанса (отсутствуют локальные максимумы на $\sim 291.7$ и $292.8 \mathrm{eV})$ и размытие структуры спектра в высокоэнергетической области, а также наличие дополнительных максимумов $\left(a_{1}\right),\left(a_{2}\right),\left(a_{3}\right)$. Все это указывает на увеличение дефектности структуры и окисление углеродных трубок [19,21]. Максимум $\left(a_{1}\right)$ отвечает $\pi^{*}(\mathrm{C}-\mathrm{OH})$-состояниям в составе гидроксильных и фенольных групп [21,23]. Максимумы $\left(a_{2}\right)$ и $\left(a_{3}\right)$ отвечают $\pi^{*}(\mathrm{C}=\mathrm{O})$ и $\sigma^{*}(\mathrm{C}-\mathrm{O})$-состояниям углерода соответственно. Сравнение кривых 4 и 5 на рис. 3 указывает на то, что увеличение флюенса ионов с $\sim 1 \cdot 10^{16}$ до $\sim 5 \cdot 10^{16} \mathrm{ion} / \mathrm{cm}^{2}$ приводит к повышению количества кислорода, химически связанного с углеродом в стенках МУНТ, в частности, наблюдается увеличение интенсивности максимума, отвечающего $\pi^{*}(\mathrm{C}-\mathrm{OH})$-состояниям. Мы предполагаем, что увеличение количества гидроксильных групп (C-OH) связано с повышением количества дефектов вакансионного типа. При этом форма спектров поглощения углеродных нанотрубок, облученных ионами аргона, позволяет говорить о более значительном искажении структуры и окислении МУНТ, чем в случае облучения импульсным ионным пучком (рис. 3 ).

Анализ плотности занятых электронных состояний вблизи уровня Ферми был проведен с использованием XPS спектров валентной зоны исходных и облученных МУНТ ионными пучками (рис. 4,a). В XPS-спектре валентной зоны исходных МУНТ (рис. 4, кривая 1) наблюдаются локальные максимумы на энергиях связи $\sim 17 \mathrm{eV}$ и $\sim 13 \mathrm{eV}$, которые отвечают C $2 s$-состояниям углерода и $2 s$-состояниям углерода гибридизированных с 
$2 p$-состояниями соответственно [24-26]. Главный максимум спектра валентной зоны исходных МУНТ на энергии связи $7 \mathrm{eV}$ сформирован гибридизированными C $2 p \sigma$-состояния углерода [24-26]. Особенность спектра в диапазоне энергий связи от 4 до $0 \mathrm{eV}$ соответствует С 2pл-состояниям углерода [24-26]. Высокая интенсивность данной особенности в спектре валентной зоны исходных МУНТ свидетельствует о высокой степени порядка кристаллической структуры стенок углеродных нанотрубок. Кроме того, форма спектра валентной зоны в низкоэнергетической области спектра указывает на наличие занятых состояний вблизи уровня Ферми, что свидетельствует о металлическом характере проводимости поверхностного слоя углеродных нанотрубок. В спектре МУНТ, облученных импульсным ионным пучком с плотностью энергии $0.5 \mathrm{~J} / \mathrm{cm}^{2}$ (рис. $4, a$, кривая 2), наблюдается небольшое увеличение интенсивности спектра в диапазоне энергий связи $\sim 24-30 \mathrm{eV}$, который отвечает $\mathrm{O} 2 s$-состояниям кислорода. Сравнительный анализ основного максимума валентной зоны (рис. $4, b$, кривые 1 и 2) исходных МУНТ и облученных с плотностью энергии $0.5 \mathrm{~J} / \mathrm{cm}^{2}$ показал незначительные изменения спектра валентной полосы: в области энергий связи от 17 до $4 \mathrm{eV}$ наблюдается снижение тонкой структуры спектра. При этом в области спектра от 4 до $0 \mathrm{eV}$ наблюдается заметное снижение интенсивности сигнала $2 p \pi$-электронов относительно спектра исходных МУНТ (рис. 4, $b$, кривая 2). Это свидетельствует об увеличении степени дефектности поверхностных слоев МУНТ, а также присоединении функциональных кислородсодержащих групп к стенкам углеродных нанотрубок [27]. Однако незначительное снижение плотности занятых электронных состояний вблизи уровня Ферми указывает на то, что нарушение кристаллической структуры и окисление углерода МУНТ носит локальный характер. Сопоставляя этот результат с данными XANES и ПЭМ, показавшими неоднородность структуры стенок МУНТ по глубине, можно заключить, что формирование структурных дефектов происходит преимущественно на внешних стенках МУНТ. Кроме этого, дополнительный вклад в плотность состояний $\pi$-подсистемы МУНТ также вносит азот присутствующий в конфигурации замещения (graphitic-like), которая является устойчивой к термическому воздействию импульсного ионного пучка [10].

В спектре МУНТ, облученных импульсным ионным пучком с плотностью энергии $1.5 \mathrm{~J} / \mathrm{cm}^{2}$ (рис. 4 , кривая 3) наблюдается снижение интенсивности $\mathrm{O} 2 p$-состояний кислорода, наличие хорошо разрешенных локальных максимумов, отвечающих С $2 s, \mathrm{C} 2 s \& 2 p$-состояниям и увеличение плотности состояний вблизи уровня Ферми. Это свидетельствует о повышении степени порядка в структуре стенок МУНТ и удалении кислородсодержащих групп с их поверхности. Данный результат хорошо согласуется с результатами количественного элементного XPS-анализа, результатами XANES- и ПЭМ-анализа. При этом отсутствие азота в обзорном XPS спектре данного образца (рис. 2, кривая 3) позволяет исклю-
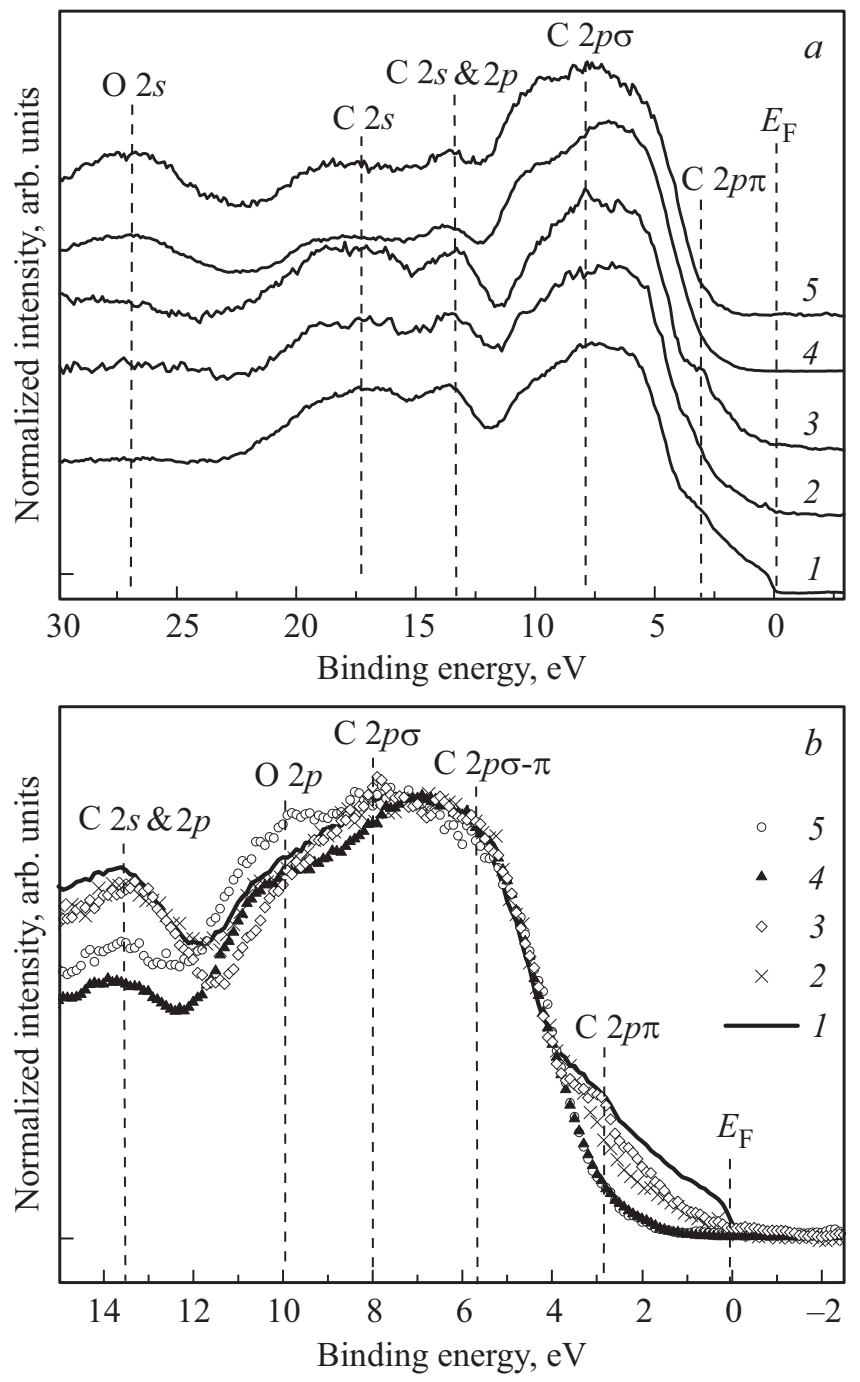

Pис. 4. XPS спектры валентной зоны МУНТ: 1 - исходных; облученных импульсным ионным пучком с плотностью энергии $2-0.5 \mathrm{~J} / \mathrm{cm}^{2}, 3-1.5 \mathrm{~J} / \mathrm{cm}^{2}$; облученных ионами аргона с различным флюенсом $4-1 \cdot 10^{16} \mathrm{ion} / \mathrm{cm}^{2}, 5-5 \cdot 10^{16} \mathrm{ion} / \mathrm{cm}^{2}$. Спектры в диапазоне энергий связи: $a-30-0 \mathrm{eV}, b-$ $15-0 \mathrm{eV}$.

чить вклад замещающего азота в плотность состояний $\pi$-подсистемы МУНТ. Таким образом, совокупность экспериментальных результатов позволяет заключить, что при облучении импульсным ионным пучком с плотностью энергии $1.5 \mathrm{~J} / \mathrm{cm}^{2}$ перестройка структуры МУНТ обусловлена преимущественно термическим отжигом структурных дефектов.

В спектрах валентной зоны МУНТ, облученных ионами аргона с различным флюенсом (рис. 4, $a$, кривые 4 и 5 ) наблюдается интенсивный максимум, отвечающий О $2 s$-состояниям кислорода. Кроме этого тонкая структура максимумов в диапазоне энергий связи $\sim 21-12 \mathrm{eV}$ существенно размывается. Как видно из рис. 4, $b$ (кривые 4 и 5) наблюдается увеличение интенсивности О $2 p$-состояний кислорода и полное отсутствие состо- 
яний в низкоэнергетической области спектра вблизи уровня Ферми. Указанные изменения, свидетельствуют о значительном повышении дефектности стенок МУНТ, разрушении $\pi$-подсистемы $s p^{2}$-гибридизированного углерода и сильном окислении поверхности углеродных нанотрубок [19]. Отсутствие состояний вблизи уровня Ферми в спектрах МУНТ, облученных ионами аргона позволяет говорить о снижении концентрации делокализованных (свободных) электронов и изменении характера проводимости. Как было показано в работе [28], функциональные кислородсодержащие группы на поверхности графитоподобных материалов являются акцепторной примесью. Следовательно, в нашем случае, полное отсутствие состояний вблизи уровня Ферми указывает на изменение характера проводимости поверхности МУНТ и возможное формирование запрещенной зоны за счет присоединения большого количества кислородсодержащих групп [29]. Сравнение спектров валентной зоны МУНТ, облученных ионами аргона с различными режимами (рис. $4, b$, кривые 4 и 5 ) показывает, что увеличение флюенса ионов приводит только к росту интенсивности О $2 p$ - и О $2 s$-состояний кислорода. При этом форма спектра в низкоэнергетической области валентной зоны (вблизи потолка валенной зоны) идентична для обоих режимов облучения непрерывным пучком ионов аргона, что свидетельствует о близких электронных характеристиках поверхности МУНТ (плотности электронных состояний, работы выхода электрона, типа проводимости и т.д.). Как было показано нами ранее в [19] облучение азотсодержащих МУНТ ионами аргона приводит к увеличению относительного содержания азота в замещающей конфигурации. Однако, на фоне существенного увеличения дефектности, окисления углерода и снижения общего количества азота, азот в замещающей конфигурации, присутствующий в стенках МУНТ, не оказывает значительного влияния на концентрацию делокализованных $\pi$-электронов.

\section{4. Заключение}

Методами ПЭМ, XPS и XANES исследовано влияние облучения непрерывным пучком ионов аргона и углерод-протонным импульсным пучком на изменение локальной атомной и электронной структуры, а также химического состояния поверхности МУНТ. Установлено, что характер изменений структуры МУНТ при облучении импульсным ионным пучком существенно зависит от плотности энергии облучения. При облучении МУНТ ионным пучком с плотностью энергии $0.5 \mathrm{~J} / \mathrm{cm}^{2}$ происходит формирование структурных дефектов и окисление углерода в поверхностном слое МУНТ. При этом во внутренних стенах МУНТ происходит отжиг дефектов кристаллической структуры вследствие термического нагрева в процессе импульсного облучения. Облучение с плотностью энергии $1.5 \mathrm{~J} / \mathrm{cm}^{2}$ приводит к повышению степени кристалличности структуры как внешних, так и внутренних слоев МУНТ за счет разрушения кислородсодержащих групп и отжига структурных дефектов, вследствие нагрева до высоких температур (до $\sim 1800^{\circ} \mathrm{C}$ ). Показано, что облучение непрерывным пучком ионов аргона приводит к образованию большого количества дефектов, искажениям кристаллической структуры МУНТ и окислению углерода с образованием различных типов функциональных кислородсодержащих групп $\left(\mathrm{C}-\mathrm{OH}, \mathrm{C}=\mathrm{O} / \mathrm{COOH}, \mathrm{C}-\mathrm{O}-\mathrm{C}, \mathrm{CO}_{3}\right)$. При этом повышение флюенса ионов приводит к значительной аморфизации структуры МУНТ и увеличению количества кислородсодержащих групп в стенках углеродных нанотрубок. Методом XPS проведен анализ изменения плотности занятых электронных состояний вблизи уровня Ферми вследствие воздействия непрерывного и импульсного ионных пучков. Установлено, что в случае облучения непрерывным пучком ионов аргона происходит изменение электронных свойств поверхности МУНТ: наблюдается снижение плотности электронных состояний вблизи уровня Ферми, и, вероятно, изменение характера проводимости. Полученные результаты показали, что применение непрерывных и импульсных ионных пучков может быть использовано для направленной функционализации электронных свойств и химической активности поверхности МУНТ при разработке наноструктурированных материалов.

Авторы выражают благодарность Ю.А. Стенькину за синтез образцов исходных МУНТ, руководству Helmholtz-Zentrum Berlin für Materialien und Energie и координаторам российско-германского канала синхротронного накопителя BESSY II (Берлин, Германия), а также руководству ОмЦКП СО РАН за предоставление оборудования для исследования образцов методом ПЭМ.

\section{Список литературы}

[1] S. Majumdar, P. Nag, P. Devi. Mater. Chem. Phys. 147, 79 (2014).

[2] H. Liu, W. Zhang, H.Yu L Gao, Z. Song, S. Xu, M. Li, Y. Wang, H. Song, J. Tang. Appl. Mater. Interfaces 8, 840 (2016).

[3] A.G. Kurenya, L.G. Bulusheva, I.P. Asanov, O.V. Sedelnikova, A.V. Okotrub. Phys. Status Solidi B 252, 2524 (2015).

[4] R. Tang, Y. Shi, Z. Hou, L. Wei. Sensors 17, 882 (2017).

[5] M. Rahmandoust, M.R. Ayatollahi. Adv. Struct. Mater. 39, 1 (2016).

[6] E. Abdel-Fattah, D. Ogawa, K. Nakamura. J. Phys. D: 50, 265301 (2017).

[7] В.А. Грибков, Ф.И. Григорьев, Б.А. Калин, В.Л. Якушин. Перспективные радиационно-пучковые технологии обработки материалов. Круглый год, М. (2001). 528 с.

[8] Ю.В. Трушин. Физическое материаловедение. Наука, СПб (2000). 286 c.

[9] M. Scardamaglia, C. Struzzi, F.J. Aparicio Rebollo, P. De Marco, P.R. Mudimela, J.-F. Colomer, M. Amati, L. Gregoratti, L. Petaccia, R. Snyders, C. Bittencourt. Carbon 83, 118 (2015). 
[10] P.M. Korusenko, V.V. Bolotov, S.N. Nesov, S.N. Povoroznyuk, I.P. Khailov. Nucl. Instrum. Methods Phys. Res. B 358, 131 (2015).

[11] В.И. Бойко, А.Н. Валяев, А.Д. Погребняк. УФН 169, 1243 (1999).

[12] Y. Isakova, A. Pushkarev, I. Khailov, H. Zhong. Rev. Sci. Instruments 86, 073305 (2015).

[13] J.F. Ziegler, M.D. Ziegler, J.P. Biersack. Nucl. Instrum. Meth. Phys. Res. B 268, 1818 (2010).

[14] S. Tanuma, C.J. Powell, D.R. Penn. Surf. Interface Anal. 43, 689 (2011).

[15] L.G. Bulusheva, A.V. Okotrub, Y.V. Fedoseeva, A.G. Kurenya, I.P. Asanov, O.Y. Vilkov, A.A. Koós, N. Grobert. Phys. Chem. Chem. Phys. 17, 23741 (2015).

[16] V.V. Bolotov, P.M. Korusenko, S.N. Nesov, S.N. Povoroznyuk, E.V. Knyazev. Nucl. Instrum. Meth. Phys. Res. B 337, 1 (2014).

[17] V.V. Bolotov, V.E. Kan, E.V. Knyazev. Procedia Eng. 152, 701 (2016).

[18] S.N. Nesov, P.M. Korusenko, S.N. Povoroznyuk, V.V. Bolotov, E.V. Knyazev, D.A. Smirnov. Nucl. Instrum. Meth. Phys. Res. B 410, 222 (2017).

[19] С.Н. Несов, П.М. Корусенко, В.В. Болотов, С.Н. Поворознюк, Д.А. Смирнов. ФТТ 59, 2006 (2017).

[20] М.М. Бржезинская, А.С. Виноградов, А.В. Крестинин, Г.И. Зверева, А.П. Харитонов, И.И. Кулакова. ФТТ 52, 819 (2010).

[21] Yu.V. Fedoseeva, A.V. Okotrub, L.G. Bulusheva, E.A. Maksimovskiy, B.V. Senkovskiy, Yu.M. Borzdov, Yu.N. Palyanov. Diam. Rel. Mater. 70, 46 (2016).

[22] Yu.V. Fedoseeva, L.G. Bulusheva, A.V. Okotrub, D.V. Vyalikh, Junping Huo, Huaihe Song, Jisheng Zhou, Xiaohong Chen. Mater. Chem. Phys. 135, 235 (2012).

[23] R.P. Gandhiraman, D. Nordlund, C. Javier, J.E. Koehne, B. Chen, M. Meyyappan. J. Phys. Chem. C 118, 18706 (2014).

[24] В.В. Болотов, П.М. Корусенко, С.Н. Несов, С.Н. Поворознюк. ФТТ 56, 802 (2014).

[25] A. Ganguly, S. Sharma, P. Papakonstantinou, J. Hamilton. J. Phys. Chem. C 115, 17009 (2011).

[26] S.C. Ray, Z.N. Tetana, R. Erasmus, W.-F. Pong, N.J. Coville. Appl. Phys. A 115, 153 (2014).

[27] K.L. Klein, A.V. Melechko, T.E. McKnight, S.T. Retterer, P.D. Rack, J.D. Fowlkes, D.C. Joy, M.L. Simpson. J. Appl. Phys. 103, 061301 (2008).

[28] G. Yang, B. Kim, K. Kim, J.W. Han, J. Kim. RSC Adv. 5, 31861 (2015).

[29] C.-H. Chuang, S.C. Ray, D. Mazumder, S. Sharma, A. Ganguly, P. Papakonstantinou, J.-W. Chiou, H.-M. Tsai, H.-W. Shiu, C.H. Chen, H.-J. Lin, J. Guo, W.-F. Pong. Sci. Rep. 7, 42235 (2017).

Редактор К.В. Емщев 